\title{
Study on the layered dusty plasma structures in the summer polar mesopause
}

\author{
Hui Li, Jian Wu, Jun Wu, Zheng-Wen Xu, and Bin Xu \\ China Research Institute of Radio wave Propagation (CRIRP), Beijing, China \\ Received: 17 March 2010 - Revised: 23 August 2010 - Accepted: 24 August 2010 - Published: 20 September 2010
}

\begin{abstract}
Traditional hydrodynamic equations are adopted to build a one-dimensional theoretical model to study the effect of gravity wave on layered dusty plasma structures formation and evolution near the polar summer mesospause region associated with polar mesosphere summer echoes (PMSE). The proposed mechanism gives consideration to the charged ice particle motion by the gravity wave modulation, making a significant contribution to the vertical transport of heavy ice particles and convergence into thin layers. And numerical results show that the pattern of the multi-layer structure depends on the ration of the initial ice particles density distribution to the vertical wavelength of the gravity waves, the ice particle size and the wind velocity caused by gravity wave. Also, the variation of ion density distribution under the influence of gravity wave has also been examined. Finally, the electron density depletions (bite-outs) layers has been simulated according to the charge conservation laws, and the results are compared to the ECT02 rocket sounding data, which agree well with the measuring.
\end{abstract}

Keywords. Atmospheric composition and structure (Middle atmosphere - composition and chemistry)

\section{Introduction}

The polar mesopause is one of the most complicated regions in the Earth's middle atmosphere for scientific study. Owing to the unique thermodynamics and dynamical structure, this region is the coldest place in the Earth's atmosphere during summer with temperatures down to and even below $110^{\circ} \mathrm{K}$ (e.g., Röttger, 1994; von Zahn and Meyer, 1998). Under certain circumstances, abundant water vapour in the lower atmosphere can ascend to the mesopause and form ice particles

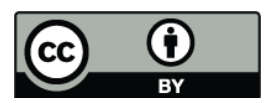

Correspondence to: Hui Li (lihui_2253@163.com) in this extremely low temperature condition (e.g., Seele and Hartogh, 1999). These ice particles coexist with the plasma of the ionospheric D-region and are charged by electron or ion attachment, resulting in the polar summer mesopause characterised as naturally weak ionized dusty plasma.

The larger ice particles scatter sunlight so that they form an intriguing Noctilucent Clouds (NLC) phenomenon, which can be observed by the naked eye. The occurrence rate of NLC has possibly been increasing since their discovery in 1885 (Backhouse, 1885; Thomas, 1989). It is believed to be an important indicator of global climate changes. Furthermore, the other phenomenon occurring in this region is the polar mesosphere ehoes (PMSE) (Eklund and Balsley, 1981; Cho and Kelley, 1993), which is also proved to be related to these ice particles. PMSE are strong radar backscatter and can be observed at frequencies from $50 \mathrm{MHz}$ to $1.3 \mathrm{GHz}$ (Hoppe et al., 1988; Röttger et al., 1998). Both the occurrence ration and the radar echo amplitude efficiency decrease with the increase of the radar frequency (e.g., Hoppe et al., 1994; Belova et al., 2007). In recent years, several theories have been put forward to explain the PMSE. A detailed discussion can be found in a review on PMSE experimental and theoretical study (Rapp and Lübken, 2004). At present, the physical mechanism for NLC is relatively clear (e.g., Thomas, 1991). However, the mechanism of PMSE has not yet been identified, which is true because of the complex constituents of atmosphere and the middle atmospheric dynamics processes in this region.

In order to investigate the mechanism of the PMSE phenomena, studies on the relationship between PMSE and ice particles behaviour have been conducted by using groundbased radars and in situ rocket sounding when the PMSE happen (e.g., Havnes et al., 1996; Havnes and Brattli, 2001; Rapp and Strelnikova, 2009). One remarkable feature of all measuring results is the fact that the charged ice particles often occur in the form of distinct layered structures and corresponding electron density depletions (bite-outs) layers.

Published by Copernicus Publications on behalf of the European Geosciences Union. 
Moreover, the strong echoes from the altitude range often correspond to these layer regions (e.g., Hocking, 1987; Alcala et al., 2001). Therefore, in order to explain the mechanism responsible for the strong echoes and in hopes of learning more about this region, the key problem is to understand the physical mechanism of these exceptional layered dusty plasma structures in the vicinity of the cold polar summer mesopause. However, until now, the mechanism causing these layered structures has remained an open question in spite of some previous attempted explanations involving the temperature variation, turbulence and the atmospheric photochemistry ionization and so on (Hill, et al., 1999; Rapp et al., 2002; David, et al., 2003; Klumov et al., 2005).

Experimental and theoretical investigations (e.g. Bremer et al., 1994; Rüster et al., 1996; Klostermeyer, 1997; Chilson et al., 1997) have shown that the gravity wave plays a very important role in producing PMSE phenomena. The upward propagating gravity wave can cool this region and transport water vapour from the lower atmosphere to the mesopause region, which provides favourable conditions for ice particle formation and growth. The above conclusion has been confirmed by several independent investigators (e.g., Thomas, 1996; Lübken, 1999). So it generally makes certain that the gravity wave is the key factor to these layered structures. Although many of the previous studies have confirmed that these layered structures are related to the gravity waves activity, some of these works (Hoffmann et al., 2005; Hoffmann et al., 2008) focus mainly on the temperature variation by the gravity wave perturbation and this variation leads to the ice particle growth, sedimentation and formation of these layers. But many of the sounding rocket measuring results (Lübken et al., 2002) show that there are no such distinct layered structures in the corresponding temperature profile. So, merely taking into account the thermodynamic variation and the gravity force may not be enough to explain these layered phenomena, especially, to explain the formation of multi-layer structures. Until now, to our knowledge, an important aspect that has never been considered is the transport of heavy ice particles under the influence of the gravity waves. A model study of breaking gravity waves (Garcia and Solomon, 1985) has indicated an updraft velocity of the order of a few centimetres per second, which is of the same order of magnitude as the fall speed of $10-\mathrm{nm}$ particles. Due to the very high neutral particle number density in the mesopause region, the ice-neutral collision can keep ice particles suspended for a long time in this region without falling and it should not be neglected.

This work considers a possible mechanism that may produce the layered dusty plasma structures in the polar summer mesopause. These ice layers ultimately produce the electron density depletion layers which may result in PMSE. The present paper, for the first time, considers the interaction of the gravity wave with the ice particle in the polar summer mesopause region, which may result in the ice particle convergence into thin layers. The organisation of the paper is as follows. The next section will present a one-dimensional theoretical model to describe dynamic process of the ice particle with the gravity waves activity, and the heavy dust grains are treated as a flowing background of negative charge. The model is solved numerically and the result is discussed with the different gravity wave parameter and ice particle size in the section that follows. Finally, this theoretical model is also tested with the ECT02 rocket sounding data and then we reach the main conclusions.

\section{Theoretical model}

The physical picture of the ionosphere, which is envisaged as the basis for the present study, composed of neutral particles, ions, electrons and the heavy charged ice particles. Considering that the vertical scale of the narrow ice particle layers is often one hundred metres to one or two kilometres, it is a very small scale compared to a horizontal wavelength of the gravity wave. The horizontal variations can be neglected. The one-dimensional continuity equation for the charged ice particle can be expressed as:

$\frac{\partial n_{d}}{\partial t}+\frac{\partial\left(n_{d} u_{z}\right)}{\partial z}=S$

Where $n_{d}$ and $u_{z}$ are the charged ice particle's vertical speed and number density, respectively, $S=Q_{d}-L_{d}$ is the source term, $Q_{d}$ is the production rate and $L_{d}$ the loss rate. As a good approximation, for simplicity, we neglect the production and loss rate in the present study. The $u_{z}$ is given by the momentum equation as:

$$
\begin{aligned}
m_{d} n_{d}\left[\frac{\partial u_{d}}{\partial t}+u_{d} \frac{\partial u_{d}}{\partial z}\right]= & -z_{d} e n_{d} E-n_{d} m_{d} v_{d n}\left(u_{d}-u_{n}\right) \\
& -\frac{\partial p_{d}}{\partial z}+m_{d} n_{d} g
\end{aligned}
$$

Where $T_{d}, m_{d}$ and $z_{d}$ are the ice particle temperature, mass and number of charge on each ice particle, $p_{d}=n_{d} k_{B} T_{d}$ is the partial pressure, $k_{B}$ is Boltzmann constant, $g$ is the gravitational acceleration, $v_{d n}$ is the collision frequency with neutral particles, $E$ is the electric field, respectively. And here $u_{n}$ denotes the velocities of the neutral particles.

Generally speaking, according to Eq. (2), the motion of charged ice particles in the mesopause is mainly governed by electric field, collision, ambipolar diffusion and gravity field. The collision frequency with the neutral atmosphere is so high. The ice particles are accelerated to their terminal speed so quickly that inertial effects will not be important. The momentum equation for ice particles then simplifies to a force balance equation in which advection of momentum can be neglected. The same consideration is taken in earlier work that modelling the plasma response to ice particle perturbations (Lie-Svendsen et al., 2003).

$$
-z_{d} e n_{d} E-n_{d} m_{d} v_{d n}\left(u_{d}-u_{n}\right)-\frac{\partial p_{d}}{\partial z}+m_{d} n_{d} g=0
$$



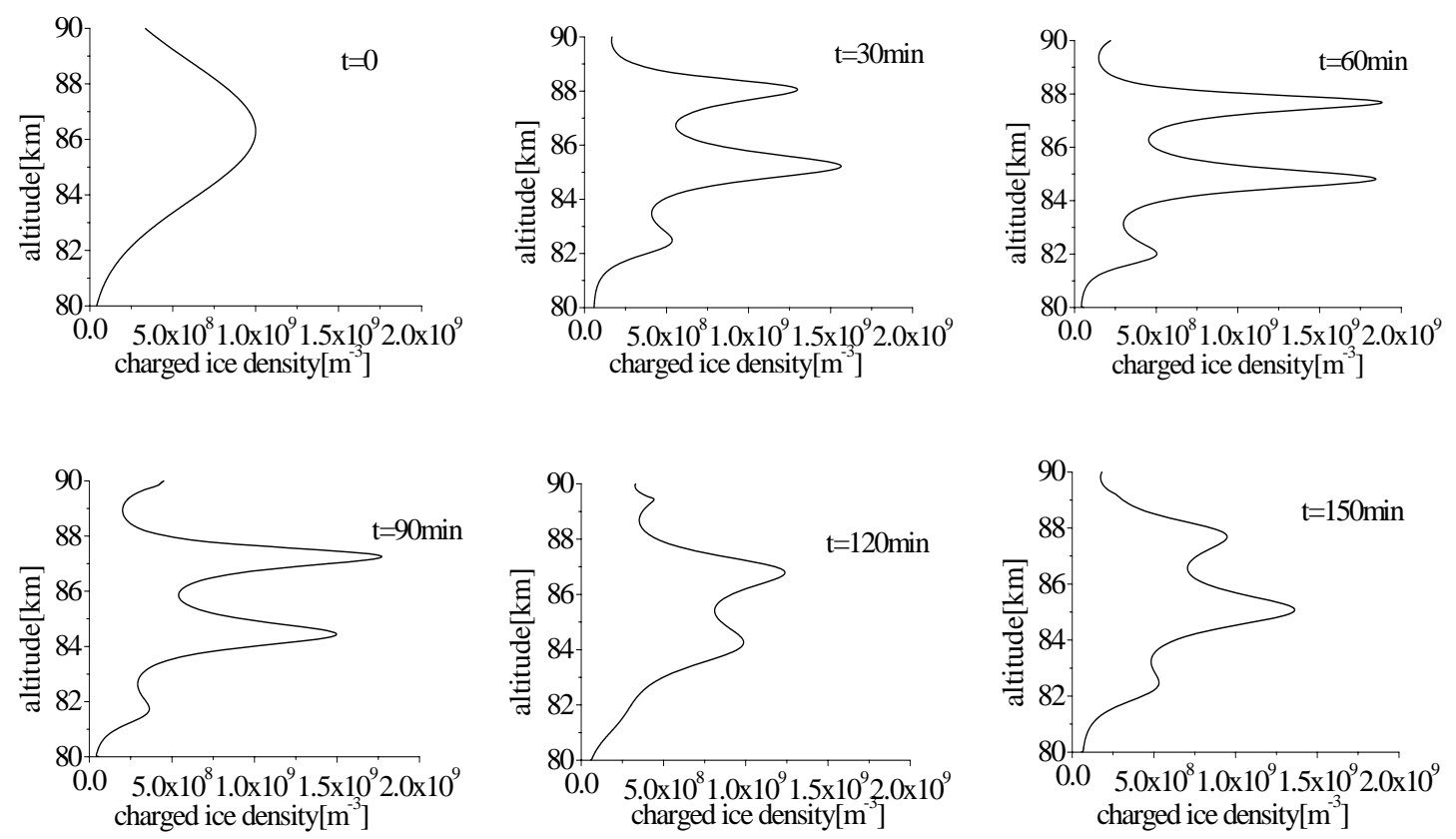

Fig. 1. The number density profiles evolution before and after modulation by the gravity waves. The time interval is $30 \mathrm{~min}(t=0,30,60$, $90,120,150 \mathrm{~min}$ ) for each panel. With the vertical gravity wavelength of $3 \mathrm{~km}$ an intrinsic period of $2 \mathrm{~h}$.

Using typical values of the above parameters, we simply compute the force acting on the charged ice particles. We find that the pressure gradient force is everywhere less than $1 \%$ of the gravitation. For single charged particles, being everywhere, the electric force is also smaller than $10^{-3}$ times the gravitation. Hence, as a good approximation, the collision with the neutral particle and the gravitation is likely to be the dominant force controlling the motion of the charged ice particles.

Generally speaking, the velocity of neutral particles $u_{n}$ in Eq. (3) is equal to the sum of the background wind and the gravity waves vertical perturbation velocities. Considering the conservation of energy, we assume that the upward propagating gravity waves grow exponentially with altitude to balance the decreasing atmospheric density. Since energy is proportional to velocity squared, the wave velocities grow as $e^{\left(z-z_{0}\right) / 2 H}$, where $H$ is the scale height of the atmospheric density. So the linear perturbations of gravity waves can be simply written in the following form (Hines, 1960):

$\boldsymbol{\omega}(z, t)=A \cdot \exp \left(\frac{z-z_{0}}{2 H}\right) \exp [j(w t-\boldsymbol{k} \cdot \boldsymbol{r})]$

Here $w=2 \pi / T$ denotes the wave frequency and $k=2 \pi / \lambda$ is the wave vector. $T, \lambda$ are the gravity wave intrinsic period and wavelength. $A$ is a ratio coefficient. Thus, the vertical wind field as a function of altitude and time can be written as $u_{z}(z, t)=\operatorname{Real}(\omega)$. And the atmospheric scale height $H \approx$ $7 \mathrm{~km}$ is assumed as a constant for the mesospause heights in the present study.
Another important consideration is the collision of the ice particles. If the standard hard sphere model (Angelo, 2005) is used to calculate the dust-neutral collision frequency then,

$v_{d n} \approx \frac{4 m_{n} n_{n} r_{d}^{2}}{m_{d}} C_{n}$

Where $n_{n}, m_{n}, C_{n}$ and $r_{d}$ are the neutral density, mass, thermal velocity and dust radius, respectively.

\section{Numerical results and discussions}

\subsection{The parameters and the solution of a reference case}

In order to approach the experiment, the calculation parameters are chosen to match the earlier observations (Rapp et al., 2002) in this paper. The vertical wavelength of the gravity wave is taken from $3 \mathrm{~km}$ to $7 \mathrm{~km}$, and the intrinsic period is some hours. The other parameters are neutral atmosphere number density $n_{n}=1 \times 10^{20} \mathrm{~m}^{-3}$ and temperature $T_{n}=T_{d}=T_{i}=140 \mathrm{~K}$, respectively. For the charged ice particles radius $r_{d}=10 \mathrm{~nm}$, and $m_{d} / m_{n} \approx 10^{5}$. Furthermore, the first-order space derivative to zero, namely $\partial n_{d} / \partial z=0$, has also been adopted to decide the upper and lower boundary condition in the numerical solutions.

Figure 1 shows the numerical results about how a broader initial charged ice particle distribution transforms into distinct thin-layer structures. Owing to the ice particle formation, mainly decided by the thermal structure in the polar mesopause and the temperature variation being a relatively slower physical process, we use the temperature profile to 

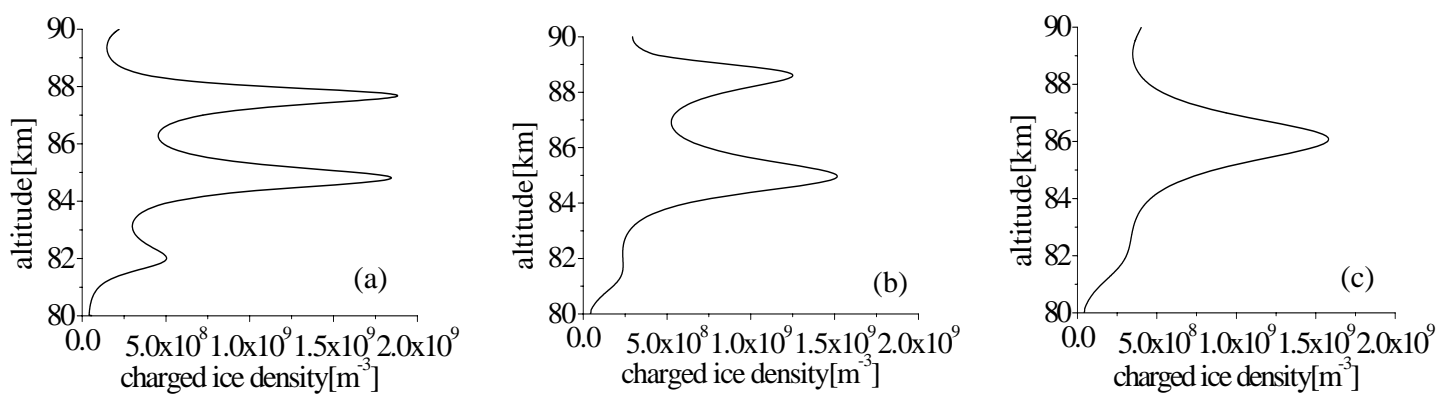

Fig. 2. The influence of vertical wavelength on the formation of ice particle layers, the wavelength $\lambda=3 \mathrm{~km}, 4 \mathrm{~km}, 5 \mathrm{~km}$, respectively.

determine the initial distribution in our model calculation. That is, the lower the temperature, the larger the ice particle density. According to the temperature profile by the sounding rocket measuring (Lübken et al., 2002), the initial vertical profile of the ice particle density can be regarded as the Gaussian distribution.

$n_{d}=n_{d 0} \exp \left(-\left(h-h_{0}\right)^{2} / 2 \sigma^{2}\right)$

Here $\sigma=2.5 \mathrm{~km}$ is the half-width of the layers. The $h_{0}=$ $86 \mathrm{~km}$ is the central height, where the height of the PMSE phenomena is very often observed (Rapp et al., 2003). And at the central height the maximum ice particle density $n_{d 0}=$ $1 \times 10^{9} \mathrm{~m}^{-3}$. As is seen in Fig. 1, the simulating time interval is $30 \mathrm{~min}$ for each panel and the model runs for $150 \mathrm{~min}$. As a reference case, the gravity wave parameter with a vertical wavelength of $3 \mathrm{~km}$, an intrinsic period of $2 \mathrm{~h}$ and the ration coefficient $A$ of $1 \mathrm{~m} \mathrm{~s}^{-1}$ and $z_{0}=80 \mathrm{~km}$ have been adopted in Eq. (4). Some detailed features are given below. After the model runs for $30 \mathrm{~min}$, the initial profile changes gradually from one peak to three-layers, which is located at $83 \mathrm{~km}$, $85 \mathrm{~km}$ and $88 \mathrm{~km}$, respectively, and the middle layer, is more outstanding. If we let the model run for one hour, two distinct layers appear, and both of the two layers have the same shape. When the model is run more than one period, the layers gradually disappear and basically go back to the initial state. Of course, with the gravity waves keeping on perturbation, the ice layers can continuously form and evolve by the gravity waves cyclic activity. In addition, since the diffusion of the charged ice particle is very slow, the layered structure of charged ice particle can be maintained for a period of time when the gravity waves disappear. These might explain why the PMSE phenomena can have a long duration in the summer mespause.

\subsection{The effect of the vertical wavelength}

The sounding rocket observations show that the ice particles appear often in the forms of one, two or even multilayers. In order to explain the origin of this multiple layers, based on the above hypothesis of gravity wave modulation, we conclude that the number of layers depends on the ratio of the initial thickness of charged ice particles to the vertical gravity wavelength. Figure 2 shows the structure evolution of charged ice particle layers with different vertical gravity wavelength $\lambda=3 \mathrm{~km}, 4 \mathrm{~km}, 5 \mathrm{~km}$, respectively, and the other parameters are the same to Fig. 1. As a reference case, the model was run for an hour. For example, when the $\lambda=3 \mathrm{~km}$, three layers can be produced (panel a), double-layers when $\lambda=4 \mathrm{~km}$ (panel b), and only one obvious single layer when $\lambda=5 \mathrm{~km}$ (panel c).

Moreover, as is seen from Fig. 2, when the number of layers decrease, the vertical thickness of the layers increase. It well coincides with observations by the sounding rocket (Havnes et al., 1996; Havnes and Brattli, 2001; Rapp and Strelnikova, 2009). Besides the vertical wavelength, other gravity wave parameters also have an influence on the formation and evolution of the layers. For example, the gravity wave periods can influence the evolution time of the ice layers.

\subsection{Effect of the ice particle size}

In fact, the number of layers not only depends on the vertical wavelength but also on the ice particles size. In the above result, we have assumed that the ice particles have a uniform radius $r_{d}=10 \mathrm{~nm}$. As is known to all, the fall speed of the heavy particle would be quicker than the smaller particle. Therefore, the different particle sizes has also been taken into account in the present study. Figure 3 is the reference case for three different sizes of the ice particles $r_{d}=10 \mathrm{~nm}$, $30 \mathrm{~nm}, 50 \mathrm{~nm}$, respectively, and the gravity wave parameters are the same as the Fig. 1.

From Fig. 3, we can see that the particle size also affects the formation of layers. When the gravity wave parameters are fixed, with the increase of the ice particle size, the height of the layers gradually falls and it becomes more difficult to form. Also, the smaller the particle is, the easier the formation of these layered structures, and the shift or disappearance is faster than the bigger particle one. Furthermore, the wind velocity caused by gravity wave is also a key factor. According to our model, the faster the wind velocity is, the faster and easier for ice particles to reach layered structures. 

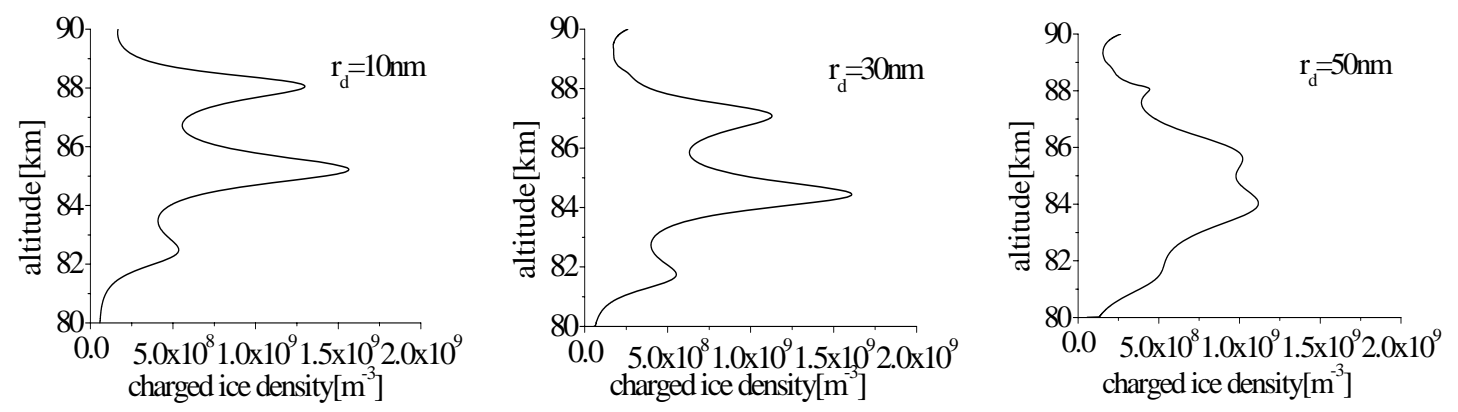

Fig. 3. The formation of layer structures with the different ice particle sizes; the size $r_{d}=10 \mathrm{~nm}, 30 \mathrm{~nm}, 50 \mathrm{~nm}$, respectively.

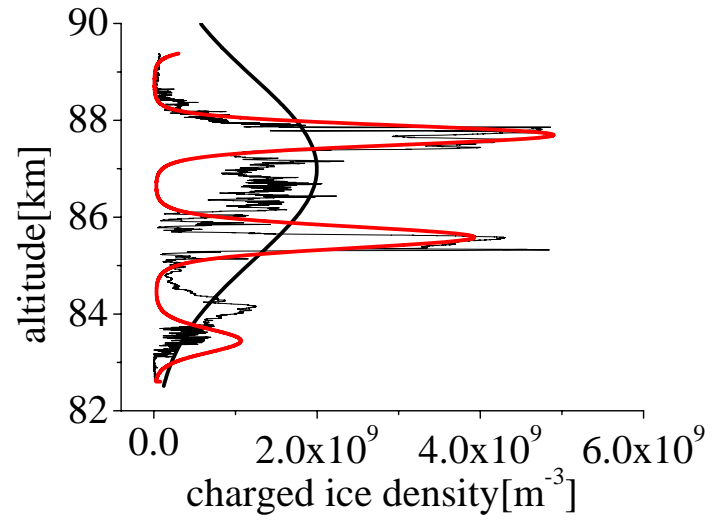

Fig. 4. The ECT02 rocket sounding data (thin black line). The model calculations results (in a red line). With the estimated vertical wavelength of $2.5 \mathrm{~km}$, the period is $4 \mathrm{~h}$.

\subsection{Electron density depletion layers and compared with ECT02 experiment data}

In order to test the above theory, we try to reproduce the experimental result recorded during the ECT02 sounding rocket campaign (Havnes et al., 1996). The initial distribution is also replaced by the Gaussian distribution with the central height at $h=87 \mathrm{~km}$ region, which corresponds to a temperature minimum value during ECT02 campaign. As is seen from Fig. 4 (the black thick line), without the measuring of the gravity wave parameter during the ECT02 campaign, we can but estimate the gravity wave parameter in our model calculation. For example, the vertical wavelength is about $2.5 \mathrm{~km}$ and the period is $4 \mathrm{~h}$, the simulation results is in Fig. 4. Then we use this gravity wave parameter to reproduce the distribution of ion and electron density and compare them to ECT02 experimental data again in the following section.

Figure 4 shows that theoretical profiles agree well with the experimental data when a reasonable gravity wave parameter is chosen. While, the location of the bottom-side layer has a little deviation compared to the data, which may be the result from the variation of the vertical wavelength with the height.

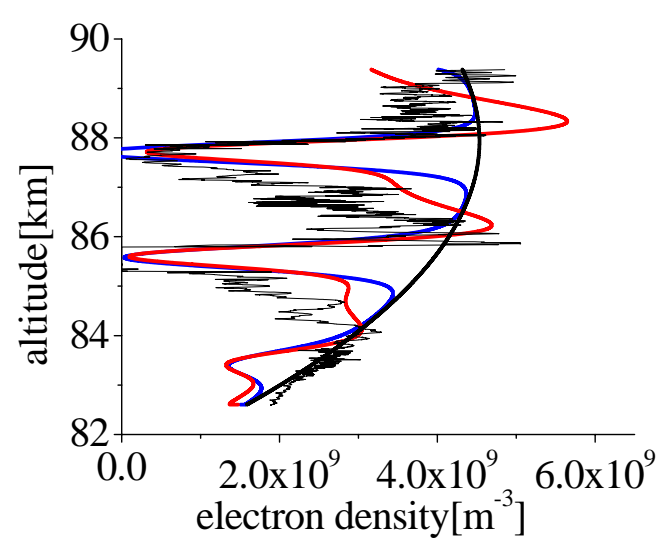

Fig. 5. Electron density profile from the ECT02 rocket data (black thin line). The undisturbed distribution (black thick line) is extrapolated from the ECT02 measuring. The model result which only considers the scavenging electron by ice particle (blue solid line). And the charged ice particle distribution together with the ion density distribution effects on the electron density distribution (red solid line).

According to the observations, electron density profiles often display bite-outs at the same height as the simultaneously observed ice layers (Ulwick et al., 1988), which also can be seen in Fig. 5 (black thin line), the date from the ECT02 campaign. At present, the reasonable explanation for these depletion layers is the scavenging of electrons by these ice particles. Generally speaking, the free electron density distribution is not only controlled by ice particle density, but can also be influenced by the ion density distribution in dusty plasma. In the above sections, we have concluded that the ice particle layers are mainly produced by the gravity wave modulation. However, some papers (e.g. Hall, 1990) have reported that the gravity wave can also effectively modulate the spatial distribution of the ion density. So the variation of ion density distribution under the influence of gravity wave would also been studied. And then, we simulate the distribution of electron density according to charge conservation laws. 


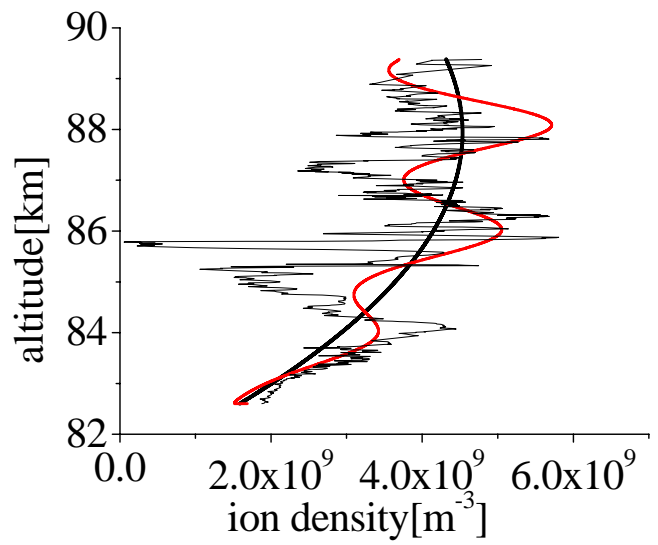

Fig. 6. Gravity wave modulates the ion density distribution (red solid line). The measuring result (black thin line) is also from the ECT02 rocket data.

While only considering the influence of gravity wave (neglecting the electric field, etc.), the vertical ion drift in the ionosphere is given by (Kirkwood, 1989):

$u_{i z}=\frac{\rho_{i} w_{\mathrm{E}} \cos I}{1+\rho_{i}^{2}}-\frac{w_{\mathrm{N}} \sin I \cos I}{1+\rho_{i}^{2}}+w_{\mathrm{z}}\left[1-\frac{\cos ^{2} I}{1+\rho_{i}^{2}}\right]$,

where $w_{\mathrm{N}}, w_{\mathrm{E}}$ and $w_{\mathrm{Z}}$ are the northward, eastward and vertical component of the neutral wind, respectively, which is mainly caused by gravity wave in the present paper, rather than the background wind. $I$ is the inclination of the magnetic field, $\rho \approx 100$ is the ration of ion-neutral collision frequency to ion gyro frequency and the other plasma parameters that have been chosen are quite similar to the polar summer mesopause. Combining the ion continue equation and Eq. (7), the gravity wave effects on the ion density distribution during the ECT02 experiment have also been calculated, among which, the gravity wave model is the same as Eq. (4) and the parameter is the same as that in Fig. 4. As is seen from Fig. 6, the calculation result is shown in a red line and the undisturbed profile (black thick line) is extrapolated from the ECT02 measuring data (black thin line). Figure 6 also shows that the ion density displays a layered structure under the influence of the gravity wave, and the variation trend of the space distribution are also well coincided with the experimental data.

According to the charge conservation laws and combining the result of Fig. 4 with that of Fig. 6, we reproduce the electron density distribution and compare with the ECT02 data again. Calculation results are shown in Fig. 5 (red solid line). It is interesting to note that, although electron density depletion layers are mainly caused by the ice particle layers, while the model calculation are more coincided with the ECT02 data, when taking into consider the variation of ion density (Fig. 6).

\section{Conclusion}

Several studies of large-scale layered dusty plasma structures at the same height as simultaneously observed PMSE have previously been considered that these layers could probably be caused by the gravity waves. But some of the explanations focus mainly on the chemical processes or turbulence resulting from the gravity wave breaking. One aspect which has not been considered is the ice particle transport by the neutral winds caused by gravity waves. Here we have assumed that the height variation of the neutral winds is mainly caused by the presence of gravity waves. It is obvious that using an exponential growth of the gravity wave model, in this paper, may result in an oversimplification and idealization of the problem. Nevertheless, the degree of agreement between this theoretical results and observations help us reach a better understanding of the physical process that are potentially responsible for the formation and evolution of these layered dusty plasma structures. As Fig. 4 and Fig. 5 shows that calculation results well agree with the experimental data when a reasonable gravity wave parameter is chosen. Furthermore, the proposed mechanism can also explain the multi-layers phenomena, which is controlled by the vertical wavelength of the gravity waves, the particle size and the winds velocity. Thus, it is suggested that the idea presented in this paper may be reasonable.

In addition, most of the in situ rocket measurements indicated that, besides the large-scale layered structures, the small-scale irregularities can extend over a wider altitude range. It is commonly in agreement that the small-scale charged ice particle and electron density irregularities are likely caused by turbulence. While, only considering the turbulence theory to explain these small-scale structures in the PMSE layer remains an open question. Based on the interaction between charged ice particle and gravity wave activity in the present study, some dusty plasma physical process, such as the dusty plasma instability, should be attempt to explain these small-scale structures, this is worth further investigation. A more detailed analysis of this question is beyond the scope of this paper.

To further confirm the idea presented in this paper, it should be taken into consideration to construct a comprehensive model to solve the problem regarding these layered structures. And the more in situ and ground-based mutualparameter observations should be obtained in the future, for example, the simultaneous measurement of gravity wave parameters and dusty plasma structures during the PMSE observations.

Acknowledgements. We would like to thank Franz-Josef Lübken and Markus Rapp, for some constructive comments. The authors also thank $\varnothing$ Lie-Svendsen and editor for their assistance in improving this paper. The authors appreciate O. Havnes, University of Troms $\varnothing$, Norway, for providing ECT02 data. This work was supported by the National Natural Science Foundation of China (NSFC) under grant 40831062. 
Topical Editor C. Jacobi thanks Ø. Lie-Svendsen for his help in evaluating this paper.

\section{References}

Alcala, C. M. and Kelley, M. C.: Nonturbulent layers in polar summer mesosphere 2. Application of wavelet analysis to VHF scattering, Radio Sci., 36(5), 891-903, doi:10.1029/2000RS002362, 2001.

Angelo, N. D.: IA/DA waves and polar mesospheric summer echoes, Physics letters A, 336(2005), 204-209, 2005.

Backhouse, T. W.: The luminous cirrus cloud of June and July, Meteorol. Mag., 20, p. 133, 1885.

Belova, E., Dalin, P., and Kirkwood, S.: Polar mesosphere summer echoes: a comparison of simultaneous observations at three wavelengths, Ann. Geophys., 25, 2487-2496, doi:10.5194/angeo-25-2487-2007, 2007.

Bremer, J., Hoffmann, P., Manson, A. H., Meek, C. E., Rüster, R., and Singer, W.: PMSE observations at three different frequencies in northern Europe during summer 1994, Ann. Geophys., 14, 1317-1327, doi:10.1007/s00585-996-1317-7, 1996.

Cho, J. Y. N. and Kelley, M. C.: Polar mesosphere summer radar echoes: Observations and current theories, Rev. Geophys., 31(3), 243-265, 1993.

David, C. F., Chris Bizon, Joseph, A. W., and Christian, K. M.: Layering accompanying turbulence generation due to shear instability and gravity-wave breaking, J. Geophys. Res., 108(D8), 8452, doi:10.1029/2002JD002406, 2003.

Garcia, R. R. and Solomon, S.: The effect of breaking gravity waves on the dynamics and chemical composition of the mesosphere and lower thermosphere, J. Geophys. Res., 90(D2), 3850-3868, doi:10.1029/JD090Id02P0385, 1985.

Hall, C. M.: Modification of the energy wavenumber spectrum for heavy proton hydrates as tracers for isotropic turbulence at the summer mesopause, J. Geophys. Res., 95(D5), 5549-5556, doi:10.1029/JD095iD05p05549, 1990.

Havnes, O., Trøim, J., Blix, T., Mortensen, W., Næsheim, L. I., Thrane, E., and Tønnesen, T.: First detection of charged dust particles in the Earth's mesosphere, J. Geophys. Res., 101(A5), 10839-10847, doi:10.1029/96JA00003, 1996.

Havnes, O., Brattli, T., Aslaksen., Singer, A. W., Latteck, R., Blix, T. Thrane, E., and Trøim, J.: First common volume observations of layered plasma structures and polar mesospheric summer echoes by rocket and radar, Geophys. Res. Lett., 28(8), 14191422, doi:10.1029/2000GL012420, 2001.

Hill, R. J., Gibson-Wilde, D. E., Werne, J. A., and Fritts, D. C.: Turbulence-induced fluctuations in ionization and application to PMSE, Earth Planets Space, 51, 499-513, 1999.

Hines, C. O.: Internal atmospheric gravity waves at ionospheric heights, Can. J. Phys., 38, 1441-1481, doi:10.1139/p60-150, 1960.

Hocking, W. K.: Radar studies of smalll scale structure in the upper middele atmosphere ans lower ionssphere, Adv. Space Res., 7(10), 327-338, doi:10.1016/0273-1177(87)90109-8, 1987.

Hoffmann, P., Rapp, M., Fiedler, J., and Latteck, R.: Influence of tides and gravity waves on layering processes in the polar summer mesopause region, Ann. Geophys., 26, 4013-4022, doi:10.5194/angeo-26-4013-2008, 2008.
Hoffmann, P., Rapp, M. M., Serafimovich, A., and Latteck, R.: On the occurrence and formation of multiple layers of polar mesosphere summer echoes, Geophys. Res. Lett., 32(5), L05812, doi:10.1029/2004GL021409, 2005.

Hoppe, U.-P., Hall, C., and Röttger, J.: First observations of summer polar mesospheric backscatter with $224 \mathrm{MHz}$ radar, Geophys. Res. Lett., 15(1), 28-31, doi:10.1029/GL015i001p00028, 1988.

Hoppe, U.-P., Thrane, E. V., Blix, T. A., Lübken, F.-J., Cho, J. Y. N., and Swartz, W. E.: Studies of polar mesosphere summer echoes by VHF radar and rocket probes, Adv. Space Res., 14, 139-148, 1994.

Kirkwood, S. and Collis, P. N.: Gravity wave generation of simultaneous auroral sporadic-E layers and sudden neutral sodium layers, J. Atmos. Terr. Phys., 51, 259-269, 1989.

Klostermeyer, J.: A height and time-dependent model of polar mesosphere summer echoes, J. Geophys. Res., 102(D6), 67156727, doi:10.1029/96JD03652, 1997.

Klumov, B. A., Morfill, G. E., and Popel, S. I.: Formation of Structures in a dusty ionosphere, J. Exp. Theor. Phys., 100(1), 152164, doi:10.1134/1.1866207, 2005.

Lübken, F.-J.: Thermal structure of the Arctic summer mesosphere, J. Geophys. Res., 104(D8), 9135-9149, 1999.

Lübken, F.-J., Rapp, M., and Hoffmann, P.: Neutral air turbulence and temperatures in the vicinity of polar mesosphere summer echoes, J. Geophys. Res., 107(D15), doi:10.1029/2001JD000915, 2002.

Rapp, M., Lübken, F. J., Müllemann, A., Thomas, G. E., and Jensen, E. J.: Small scale temperature variations in the vicinity of NLC experimental and model results, J. Geophys. Res., 107(D19), 4392, doi:10.1029/2001JD001241, 2002.

Rapp, M., Lübken, F.-J., and Blix, T. A.: Small scale density variations of electrons and charged particles in the vicinity of polar mesosphere summer echoes, Atmos. Chem. Phys., 3, 13991407, doi:10.5194/acp-3-1399-2003, 2003.

Rapp, M. and Lübken, F.-J.: Polar mesosphere summer echoes (PMSE): Review of observations and current understanding, Atmos. Chem. Phys., 4, 2601-2633, doi:10.5194/acp-4-2601-2004, 2004.

Rapp, M., Strelnikova, I., Strelnikov, B., Latteck, R., Baumgarten, G., Li, Q., Megner, L., Gumbel, J., Friedrich, M., Hoppe, U.P., and Robertson, S.: First in situ measurement of the vertical distribution of ice volume in a mesospheric ice cloud during the ECOMA/MASS rocket-campaign, Ann. Geophys., 27, 755-766, doi:10.5194/angeo-27-755-2009, 2009.

Röttger, J., Hoz, C. L., Kelley, M. C., Hoppe, U.-P., and Hall, C.: The structure and dynamics of polar mesosphere summer echoes observed with the EISCAT $224 \mathrm{MHz}$ radar, Geophys. Res. Lett., 15(12), 1353-1356, doi:10.1029/G1015i012p01353, 1988.

Röttger, J. and Larsen, M. F.: UHF/VHF radar techniques for atmospheric research and wind profiler applications, in Radar on Meteorology, Am. Meteorol. Soc., A90, 235-281, 1990.

Röttger, J.: Middle atmosphere and lower thermosphere processes at high latitudes studied with the EISCAT radars, J. Atmos. Terr. Phys., 56, 1173-1195, 1994.

Rüster, R., Czechowsky, P., Hoffmann, P., and Singer, W.: Gravity wave signatures at mesopause heights, Ann. Geophys., 14, 11861191, doi:10.1007/s00585-996-1186-0, 1996. 
Seele, C. and Hartogh, P.: Water vapour of the polar middle atmosphere: Annual variation and summer mesosphere conditions as observed by ground-based microwave spectroscopy, Geophys. Res. Lett., 26(11), 1517-1520, doi:10.1029/1999GL900315, 1999.

Svendsen, Ø. L., Blix, T. A., and Hoppe, U.-P.: Modeling the plasma response to small-scale aerosol particle perturbations in the mesopause region, J. Geophys. Res., 108(D8), 8442-8476, doi:10.1029/2002JD002753, 2003.

Thomas, G. E. and Olivero, J. J.: Climatology of polar mesospheric clouds 2, Further analysis of Solar Mesospheric Explorer data, J. Geophys. Res., 94(D12), 14673-14681, doi:10.1029/JD094iD12p14673, 1989.
Thomas, G. E.: Mesopheric clouds and the physics of the mesopause region, Rev. Geophys., 29, 553-575, 1991.

Thomas, G. E.: Global change in the mesosphere-lower thermosphere region: Has it already arrived?, J. Atmos. Sol. Terr. Phys., 58, 1629-1656, 1996.

Ulwick, J. C., Baker, K. D., Kelley, M. C., Balsley. B. B., and Ecklund, W. L.: Comparison of simultaneous MST radar and electron density probe measurements during STATE, J. Geophys. Res., 93(D6), 6989-7000, doi:10.1029/JD093iD06p06989, 1988. 